\title{
Managing cultural change: the challenge of merging library services, curriculum development and academic professional development
}

\author{
Sue McKnight \\ Executive Director, Learning Services \& University Librarian \\ Deakin University \\ Geelong, Australia \\ suemck@deakin.edu.au
}

\begin{abstract}
The paper outlines a number of processes that have been implemented by Learning Services at Deakin University to gain significant and sustained cultural change amongst staff in a blended organisation, comprising the university library service, the curriculum design and development functions and those of academic staff development. The processes involve customer discovery workshops to identify "customer value packages", strategic planning and performance tracking based on objectives that deliver customer value, and the identification of shared staff values that guide behaviour within Learning Services and with customers.
\end{abstract}

\section{Introduction}

Change is endemic. It is rapid, and often has significant implications. Some staff are "change junkies" and others are less able to embrace change. However, the impact of change on staff in academic libraries is profound, and management have a role in making sure that staff are better able to understand, participate in and manage the change themselves.

Academic libraries are dealing with a multitude of change agents, from budget constraints, increasing use of, and rapid change in information technologies, changes in scholarly publishing, and demands for greater accountability and benchmarking, to devising and implementing new services for an increasingly sophisticated and demanding user population. Many academic libraries are also dealing with converging organisational and service structures, with libraries combining with information technology service departments and teaching support and curriculum development units.

This paper deals with cultural change, which has been described as "Lasting structural and social changes (within an organisation or set of linked organisations), PLUS Lasting changes to the shared ways of thinking, beliefs, values, procedures and relationships of the stakeholders."

This discussion is primarily focused on the internal aspects of managing cultural change. It focuses on the cultural change associated with creating a working environment that is a blend of professionals, re-engineering processes, creating new teams, and the overarching need to establish a shared set of values that defines the blended organisation.

Much of the internal cultural change has evolved from a focus on the prime customer groups, of understanding their value packages (their hierarchy of needs and desires) and of discovering what irritates them about existing 
practices, services and resources. The research undertaken to define the customer value packages provided the evidence that drove the internal cultural change.

\section{Background of Deakin University and Learning Services}

\section{The University}

Deakin's vision is to be Australia's most progressive university, internationally recognised for the relevance, innovation and responsiveness of its teaching and learning, research, partnerships and international activities.i

Deakin University was established in 1974 and began teaching in 1977 . The University has 70,000 students enrolled each year, and specialises in studentcentred education and lifelong learning. It has six campuses across the State of Victoria, three in Melbourne, the capital of the Australian State of Victoria, two in the second largest city in the State, Geelong, which is $70 \mathrm{~km}$ from the capital, and one in Warrnambool, a thriving regional centre $200 \mathrm{~km}$ from Geelong. Deakin has five faculties: Arts, Business and Law, Education, Health and Behavioural Sciences, and Science and Technology. It offers awards from undergraduate degree to research and professional doctorates.

All Deakin students have choices about the way they study. Students can attend lectures on campus and receive face-to-face teaching, but thousands of busy professionals have discovered a different way to study - using flexible, online course delivery. Students receive comprehensive study packages including state-of-the-art computer-aided learning, simulations and videos.

Flexible delivery allows students to study on campus or off campus, full time or part time, or using a mix of study modes. With Deakin, students can take a degree in many fields, undergraduate or postgraduate, from anywhere in the world - at home, or where they work. Students studying on campus or off campus take exactly the same Deakin degree.

In 1993, Deakin University created Deakin Australia (now Deakin Prime), a wholly owned subsidiary company, with a brief to tailor education and training to the needs of corporate clients. It works with a broad range of national and international corporations, professional associations and government agencies. Deakin Prime has grown to become Australia's leading provider of education and training for organisations, with more than 40,000 people enrolled through partnerships and contracts at any one time.

In 1995 Deakin was named 'Australian University of the Year' for its innovative use of information technology in teaching. In 1997 it won a five-star rating from the Graduate Careers Council of Australia. In 1999 Deakin became the only university in Australia to be awarded the coveted University of the Year twice - this time for its productive partnerships with business and industry. 


\section{Learning Services}

Learning Services was formed at the end of 2000 from the merger of what was the Office of Flexible Learning, the Centre for Academic Development, Learning Resource Services and the Library. Today, Learning Services comprises four quite different organisational units:

The Teaching \& Learning Support Unit is responsible for educational design, academic professional development, management of the enterprise-level learning management system, and research and evaluation on teaching scholarship and pedagogy.

Learning Resources is responsible for translating the education designs for curriculum material into the actual resources used by teachers and learners, whether interactive online environments or static web pages, multimedia CD-ROMs, audio and video tapes, printed material, and accessible curriculum resources for students with disabilities.

Access and Information Resources incorporates the traditional technical services functions of a library (acquisition, cataloguing, collection management) but is also involved, more and more, with managing information resources and systems for digital objects (eReadings, digital information for students with a disability, and digital course materials, with an emphasis on complying with copyright, intellectual property and disability discrimination legislation and policies).

Library Services is the traditional public services of the library. It is responsible for reference and information services, resource delivery including loans, inter-campus and off-campus loans, inter-library loans and shelving, the information literacy and liaison programs, and collection development.

As of July 2002, Learning Services employed approx. 300 people in 230 effective full-time positions across six campuses. There is a wide variety of professional categories represented within Learning Services, including: librarians and library technicians; academic staff with specialist skills in education design, research and evaluation, and professional development; instructional designers (many with teaching experience); graphic designers; programmers and www developers; system and database administrators; photographers; editors/material developers and publishing support officers; printers and finishers; video and audio producers; accountants; business managers; copyright experts; and administrative and clerical staff.

As you can see, there is quite a range, and if you consider the philosophical backgrounds of the professional areas, you start to see the challenges in bringing together these diverse sets of cultures and experiences. However, we believe we can deliver greater value, or be more than the sum of the 
individual parts of Learning Services, by working together in the new online and digital environment.

\section{Why must we change?}

As with most organisations, universities are undergoing significant change due to the increasing "massification" of tertiary education, the increasing globalisation of higher education, pressures due to space and financial constraints, and the increasing commercial imperative to seek new markets and raise additional revenue. These, together with rapid changes in informational technologies and increasing expectations of students, mean that staff employed in the higher education sector must cope with constant change, not only in work processes but also in the way we think of students and other staff members. Universities are increasingly reflecting the language, policies and processes of the business world.

It is worth highlighting that over the last ten years, Deakin University has undergone significant organisational change, becoming a blended organisation, comprising the original Deakin University (Geelong), which was itself a merger of two organisations, the Warrnambool Institute of Advanced Education (in Warrnambool) and Victoria College (in Melbourne), another blended organisation. Thus, the parent organisation has a variety of cultures, reflecting the different origins of the constituent members.

The Library, as an organisational unit, has had a relatively stable life, undergoing a number of relatively minor internal reorganisations but retaining its strong "library" tag. However, the other components of the organisational unit that I now manage have had a long history of restructure and organisational change for a variety of reasons. My belief is that the frequent and destabilising restructures were the result of: a lack of vision as to the role of the groups within the University, and a clash of professional cultures and too much emphasis on professional boundaries, which result in work silos, rather than focusing on the needs of students and academic staff and working together to deliver these needs.

Therefore, the bringing together of a relatively stable, high profile and well respected Library, serving students and academic staff as individuals, with a group of organisational units that rarely interacted with students and whose services, while of excellent quality, were only accessed by a select few academic staff, created an interesting challenge for managing cultural change.

There were also external pressures for change that were driving a reassessment of our working relationships within Learning Services. These were primarily driven by changes to the Australian Copyright Act and the Digital Agenda Act, regarding the communication of electronic information to students. Both the Library and Learning Resources Services were involved in managing copyright compliance. Both were involved with digitising material for students, for use via the e-Readings (formerly e-Reserve) service of the Library and for delivery of curriculum material to those students with a print 
disability. The legislative changes required a much more coherent approach to the communication/delivery of copyright material to students.

Rapid changes in IT infrastructure are also leading to the convergence in systems that deliver information to students. One of my favourite sayings is "Students don't know, or care, where the curriculum ends and the support information resources begin." As we move progressively into an online, or at least online enhanced environment for teaching and learning, there is a blurring of the services and resources delivered from the Library's integrated management system, the learning management system (course management system), and the digital object repository. In a University like Deakin, that has been creating curriculum resources for delivery to remote students, whether in print or other multi-media or online formats for many years, there is also the emerging need to link the course materials planning and production system with the digital object repository, to link the digital object repository to a digital printing system, and also to integrate warehousing and dispatch functions. All these developments are adding further weight to the need to manage significant cultural change, as staff have had to develop new work processes and new skills, develop understandings of new customers, and form new teams within the organisation, while at the same time working with new partners both within Learning Services and also within the wider University.

A further development within Deakin University is the move to deliver more and more learning opportunities online. The need to ensure tightly integrated, online learning environments, linked to all the traditional support services, has caused a re-evaluation of how we design learning spaces for students, so as to embed access to information resources and information literacy training in particular, with the traditional curriculum resources of subject outlines, study guides and readers.

The final catalyst for change that I will mention is the changing financial climate of universities in Australia, and I assume across the world, where we are trying to do more with less, where we are conscious, as managers, of delivering a significant return on investment and the need to maximise use and value-adding of existing assets. This business approach to managing staff and resources creates pressure to change often long-held attitudes in the work environment.

\section{Change to What? Understanding Customer Needs}

My management philosophy can be summed up as understanding our customers, and knowing what really matters to them. To achieve this, we ask the customers. By understanding the environment in which we work, by understanding the values of our customers, by identifying new or changed services that would help deliver greater value for our customers and reduce their irritation level, we can develop a plan for action.

By involving staff in this customer research, by seeking their analysis of the research findings on what adds value for the customer, by their participation in teams established to define what change is required within the organisation to 
deliver the customer value package, we create an internal environment that is not only ready for change, but which is driving the change from the ground up, rather than imposed from management above. In this way, there is a much greater chance of staff "buy-in" and the change process is much more likely to be successful and sustaining.

The process involves conducting "customer discovery workshops"iii where customer groups (undergraduate, postgraduate coursework, postgraduate research, off-campus, academic staff etc) participate in facilitated workshops. Learning Services staff also attend, sitting in the background, listening to the feedback, but not commenting as this would stifle comments from the customers. In the first part of the focus group workshops, the participants identify, in silence and individually, the irritants that they perceive about the existing services. This way, the issues are identified but there is no "you think that's bad, listen to what happened to me" situation. These comments are then gathered for analysis after the workshops.

Then the participants are lead through a visioning exercise, where they are asked to imagine a time, three to five years on, when they have been successful in their endeavours at university, and they are asked to identify what services, provided by Learning Services, helped them achieve their success. This exercise, through a prioritising process, leads to the identification of the services and resources that are most valued. The participants are then asked to rate the current performance of Learning Services in delivering the identified services. This results in a hierarchy of value elements and a gap analysis on perception of current performance, which can then be analysed to identify strategies to close the gaps.

When Learning Services was formed, the Library had been conducting customer discovery workshops for a number of years. The staff were used to the process and had been successful in acting upon the feedback. With the formation of Learning Services, there was a need to conduct similar workshops focusing on the new, wider range of services that had not been previously identified in the Library's customer research activities.

For Learning Services the top value elements are, in order of highest to lowest importance:

\section{Library Value Factors}

- Relevant, current, accessible book collection

- Easy access to more online Library resources

- Sufficient copies of key texts

- Approachable, knowledgeable, competent staff

- Access to and availability of journals

- Affordable, flexible and reliable photocopying and printing

- Reliable, up to date IT computer support

- Timely access to Library staff and online help

- Environment conducive to study

- Adequate opening hours

- Library skills training to find information

- Clear signage 
Teaching \& Learning Support Unit/Learning Resources Value Factors

- Up to date practical, education advice and support

- Timely responsive service

- Working together

- Adequate appropriately managed resources

- Focus on quality and improvement

- Training and Professional development responds to my needs

- Flexible service delivery

- Friendly competent co-operative staff

- Commitment to facilitation of on-line delivery

- Knowledge of and access to staff and services

The process described has been the framework used to deliver cultural change. It is based on asking the customer, and not assuming that we know what is good for the customer. It results in challenges to existing policies and work practices, and engenders a greater value on teamwork than would otherwise be evident, as customers invariably do not distinguish between particular aspects of the service, perhaps delivered by different parts of the organisation. What they describe is the outcome of an end-to-end process, and to deliver the value, all parts of the organisation, in our case, Learning Services, must work together.

Inter-disciplinary teams are formed, often involving customers as well, to analyse the customer value feedback results. These teams review existing work practices and identify new ways of delivering the service to remove irritants and add value. By listening to the feedback of customers, Learning Services staff realise that changes are necessary, and that, perhaps, they could improve on what they currently do or deliver. The customer feedback research forces an honest appraisal of services and resources and highlights, from the customers' perspective, why change is necessary. Thus, the changes are customer driven, and not by management in a top down approach.

Prior to the merger that formed Learning Services, the Library had adopted a "purpose statement", rather than a vision or mission statement, that guided thoughts and actions. This purpose statement was "We help people learn." After the merger that formed Learning Services, this purpose statement became "We help people teach and learn", which reflects the direct role of Learning Services in assisting academic staff to develop curriculum material and the role of the group in delivering academic professional development. I suggest, that had the Library not merged with the other groups, it would still have changed its purpose statement to this one, as librarians are becoming increasingly involved in the design of integrated online learning environments and in delivering, in the classroom or on the web, information literacy training to students (and academic staff).

Customer discovery workshops are now being supplemented by smaller, more frequent feedback sessions. Learning Services staff use data from the customer research to identify the objectives that will deliver the customer 
value packages, and these then form the basis of the Learning Services Strategic Plan. The Strategic Plan is written in the format of the Balanced ScoreCard (BSC) with the four perspectives: Financial, Customer, Internal Processes and Learning \& Growth, ensuring that all aspects of our operations receive attention so as to fulfill the customer value packages. ${ }^{\text {iv }}$

The objectives contained in the current Learning Services Strategic Plan, including the Library operations, are:

\section{Customer Perspective}

\section{C1. Satisfy our customers}

Contribute to the success of our customers and continually improve customer satisfaction by focused delivery of the selected value models, i.e. what they believe is important.

\section{C2. Be First to mind}

Develop our reputation and profile such that Learning Services is first to mind for assistance in teaching and learning within Deakin. We are the acknowledged leader, the provider of choice. Customers associate our products and services with excellence. Customers know, understand, value and use our services and resources.

\section{C3. Extend our reach}

Increase the numbers of people and levels of interaction with our services and resources. Expertise, resources and systems of Learning Services underpin the University's knowledge management initiatives and strategic priorities.

\section{Internal Processes Perspective}

\section{I1. Dramatically improve core processes}

Dramatically improve the efficiency and effectiveness of core processes which deliver customer value packages.

Dramatically reduce the end-to-end time of key core processes.

\section{Continually improve productivity}

Strive to improve productivity to achieve savings that can be applied to further enhance our productivity.

\section{Learning \& Growth Perspective}

\section{L1. Invest in people}

Invest in selecting, retaining and developing our people in a supportive and innovative work environment, where they are recognised and rewarded for excellence.

\section{L2. Strategy driven technology}

Exploit new and existing technologies to maximise productivity and value.

\section{L3. Living our values}

Demonstrate commitment to our purpose and values through our daily behaviours, policies and practices.

\section{Financial Perspective}

\section{F1. Maximise asset utilization}

Continually seek ways to maximise the use of our assets and resources to deliver greater value to our customers and the University and minimise unproductive overheads.

\section{F2. Develop beneficial partnerships}

Maintain and seek beneficial partnerships that enhance our services and resources. 


\section{F3. Drive change and decision-making}

Play a key role in the success of the University's planning and decision-making.

Ensure University decisions and directions are influenced by Learning Services' vision and requirements.

Ensure that sufficient funds are allocated to support our strategic priorities.

An important aspect of using the BSC framework is the focus on performance measurement. Learning Services is currently implementing the CORVU balanced scorecard software so that all staff can track our performance on a regular basis. I have to admit that we have struggled to identify the most appropriate measures to track our performance, but we are getting closer to having the right mix of lead and lag indicators so that we can identify problem areas (areas where our performance is not what we expect or desire) early enough so that remedial action can be taken before it is too late to have a positive impact.

The BSC representation of our strategic planning objectives and performance is a great way to share results and to aid communication, both to staff within Learning Services and also with our customers and stakeholders. The performance is displayed in a www format, linking the customers' values (from the customer research), with the Learning Services objectives and with the operational level strategies to action the objectives, and finally to the targets and associated measures of all units within Learning Services.

This very public way of displaying what we are trying to achieve, how we are going to achieve the objectives, and the actual performance is a great way of facilitating cultural change. Staff see how their individual contributions link to the overall goals of the organisation, how they must work as a team to deliver the customer value packages, and they learn to think in an end-to-end service model rather than simply focusing on their "small bit" of the business of Learning Services.

\section{Roadblocks to Cultural Change}

Despite the idealistic rhetoric here, the reality is that Learning Services is not perfect, by any means, but we are doing very well when compared to other parts of our University. The processes employed go a long way towards minimizing the impact of internal politics and personal egos, which can be significant blockages to change.

A major impediment to cultural change that was encountered was the gulf between the Library's preparedness to work within the customer discovery research and BSC framework and that of the other parts of the merged Learning Services. The Library had had four years of experience of working in this way, and the others were starting from scratch. Therefore, we experienced frustration from Library staff as we worked to bring everyone up to the same level of understanding. Library staff felt that they were standing still, and not progressing, while this was being done. There was jealousy towards the Library because of its very high reputation and standing within the University. 
The next impediment was having all Learning Services staff understand the need to change. This was overcome, in part, by involving staff in the customer discovery workshops and subsequent analysis of results. However, there are still many staff who have not taken part in this process, and only over time will they have personal experience of listening to customers and accepting the feedback as the basis for action for continuous improvement. In the meantime, the staff "champions", who have been involved with the process, act as advocates with their work colleagues.

Centrally organised staff development activities, including Change Management training and Customer Service training, have been conducted. A large number of Learning Services staff have participated in these activities.

In the process of analysing results of the customer value feedback, and in the subsequent reviews of our core processes, it became apparent that we have a clash of professional cultures, with academic staff employed within Learning Services placing more emphasis on the researching, thinking and evaluation of actions, while those in the Library and in Learning Resources, in particular, more focused on action. By understanding that we are all involved in a chain of actions that lead to an outcome, a result, a service or product that is delivered to the customer (learner or teacher), we are better equipped to value our own differences and see how everything must fit together to deliver what the customer wants and values. It is slowly breaking down a "them and us" mentality.

There are also language differences and poor communication. Some words mean different things in different professional disciplines and we are trying to develop a common vocabulary so that there is clarity and understanding when we use terms. Poor communication is not new in any organisation, and especially one that is so geographically dispersed. We will never be perfect, but we are striving to improve communication amongst work groups and across campuses so that there is broader understanding of all parts of the organisation, and that information is available for all to interpret and use as required. There is extensive use of an Intranet to share information, and global emails to all staff keep people abreast of important news.

Finally, there are entrenched practices and past histories that impede cultural change. There is the potential for mistrust and misinterpretation based on past experiences. Only time and positive experiences will overcome this. However, by demonstrating success through high levels of customer and stakeholder satisfaction, we start to share "wins" and demonstrate the value of partnerships, which help to develop trust and shared, positive histories.

Success breeds success.

\section{Shared Staff Values}

During 2001, the management team realised that it would aid our cultural change if we could go through a similar exercise as we had done with our customers, to understand what we value as individuals working in Learning 
Services. Research by St. Hubert Saint-Onge $v$ indicates that by identifying shared values, and articulating these within the workplace, there is a great deal more synergy between different work groups. The glue, binding all aspects of a successful organisation, is Shared Values.

Over 170 Learning Services staff participated in facilitated workshops to identify the values that guide our behaviour at work. A small team took the results of these workshops and developed the final list of our core values. These are:

\section{We commit to our colleagues and clients. We take responsibility. \\ We willingly share knowledge and skills. We connect ideas to action.}

To be able to demonstrate that there was a strong and common set of values, within Learning Services, was very important. Despite the different professional backgrounds, we were one organisation, with common values and philosophies, delivering quality services and resources to the University community. At this moment, we are in the process of conducting workshops with each workgroup so that they can articulate, for themselves, in their particular situation, how these values will be demonstrated in the workplace. We are convinced that this process will go a long way towards breaking down the few barriers that still exist between the merged entities that make up Learning Services.

When I return to work from this conference, my management team will be considering the introduction of monthly workgroup awards that encourage demonstration of our shared values. This way we are hoping to internalise our values, constantly demonstrating that we consider these are important, and to reward staff who "walk the talk".

\section{Moving On}

I believe we have been successful in achieving cultural change. Staff are aware of our customers' values, are focused on delivering the customer value packages, and are proud of their own and their group's contributions to achieving these. There is a common framework to discuss work and we have improved the tracking of our performance.

Staff morale has been improved. There is a greater understanding of how all the bits of Learning Services fit together. There is less concern about future change, as rather than change being seen as a "bad thing", staff are empowered to make change because it improves our performance in achieving the customers' needs. They now understand the reasons for the change, and that the changes will have a positive impact on our customers.

As a result of the focus on customer needs, we have improved general management practices: Strategic Plans are "strategic"; operational plans link to the strategic plan; performance measurement tracking is used and reports on performance are available on the www for all staff to see; budgets (try to) 
follow strategic decisions; and skills audits and staff development plans are informed by our strategic directions.

The net result is that we enjoy a high reputation within the University for being customer focussed, for delivering what is required, and for demonstrating sound financial and staff management. This brings benefits to Learning Services when additional funds are required for projects or when budgets are being considered for cuts. Because we can link our plans and budgets to the direct needs of our customers, we have a far greater chance of gaining additional resources or surviving funding cuts. In addition, we have developed our reputation as expert service providers.

The cultural change has been profound, and is still ongoing. Given the environment in which we work, further significant change is anticipated. However, we look upon the future as an opportunity to deliver even better services and resources.

In some ways we have dared to be different. We have behaved more like a commercial business rather than like a university or traditional service organisation. However, it has been, and will continue to be, worth it.

"Behold the turtle, he makes progress only when his neck is out". Confucius

\footnotetext{
'Alison Scammell, "The Bigger Picture: cultural change and the eLib programme", International Institute for Electronic Library Research, De Montfort University, Milton Keynes, UK

http://www.ukoln.ac.uk/services/papers/bl/ans-1997/scammell/iap-html/tsld001.htm

ii Deakin University Strategic Planning Framework http://www.deakin.edu.au/vc/vc/strategic/strategic.php
}

iii The process is owned and facilitated by consultants, Austin Thompson and Associates, Sydney, Australia, who have been working with the Library, and now Learning Services, since 1996.

iv Robert S. Kaplan, David P. Norton, "The balanced scorecard: translating strategy into action", Boston, Mass., Harvard Business School Press, 1996.

" Saint-Onge, Hubert, "Creating a knowledge-driven enterprise", workshop notes, sponsored by Clarica, and presented in Sydney, Australia, July $4^{\text {th }} 2001$. 